\title{
Do transfusion requirements increase after the diagnosis of vasospasm in patients with aneurysmal subarachnoid haemorrhage?
}

\author{
Lashmikumar Venkatraghavan, Sarah Tymianski, Jeffrey Singh
}

\begin{abstract}
Background: Many patients experience impaired cerebral oxygen delivery secondary to vasospasm and delayed cerebral ischemia following aneurysmal subarachnoid haemorrhage (SAH). Anaemia is common after SAH affecting up to $50 \%$ patients, which may decrease cerebral oxygen delivery and is associated with worse clinical outcomes. Transfusion of allogeneic red cells increases the oxygen content of the blood but it not consistently associated with improved physiologic markers of clinical outcomes. The threshold for transfusion is not clear in patients with SAH. A recent survey found that most physicians would alter their transfusion threshold in SAH patients who develop delayed ischemia. The objective of our study is to identify the predictors of transfusion and to determine if the diagnosis of delayed ischemia increases the transfusion rates in patients with aneurysmal subarachnoid haemorrhage. Materials and Methods: We retrospectively reviewed the charts of 100 consecutive patients with SAH who were admitted to ICU for mechanical ventilation, and collected demographic and clinical data. Data were analyzed for the association between clinical factors and transfusion the differences in transfusion between the patients with and without vasospasm. Statistical methods included the $t$-test, univariate analysis and multivariate analysis. Results: Data from 96 patients were included in the analysis. Incidence of anaemia haemoglobin $(\mathrm{Hb})<100 \mathrm{gm} / \mathrm{l}$ and vasospasm were 67\% (64/96) and 39\% (38/96) respectively. Of 64 patients with anaemia, 27 patients received transfusion, while 38 patients did not receive a transfusion. The transfusion rates were similar between those who had vasospasm and who did not. However, out of the 14 patients with vasospasm who received a transfusion, II patients had been transfused after experiencing vasospasm, while only 3 were transfused before. On multivariate analysis only female sex, starting $\mathrm{Hb}$ levels and lowest $\mathrm{Hb}$ levels were found to be predictors of transfusion. Presence or absence of vasospasm was not found to be a predictor. Conclusions: From our retrospective review, we conclude that the incidence of anaemia is higher in patients with vasospasm. Sex and starting and lowest $\mathrm{Hb}$ levels were the only predictors of transfusion likelihood in aneurysmal subarachnoid haemorrhage while presence of vasospasm was not.
\end{abstract}

Key words: Anaemia, blood transfusion, subarachnoid haemorrrhage, vasospasm

\begin{tabular}{|l|l|}
\hline \multicolumn{2}{|c|}{ Access this article online } \\
\hline Quick Response Code: & Website: \\
\hline & www.jnaccjournal.org \\
\cline { 2 - 2 } & \\
\hline
\end{tabular}

\section{INTRODUCTION}

Anaemia is common after subarachnoid haemorrhage $(\mathrm{SAH})$, occurring in up to $50 \%$ of patients and is associated with worse outcomes, including delayed cerebral ischaemia, cerebral infarction, death and functional dependency. ${ }^{[1,2]}$ Clinical vasospasm (VS) after SAH occurs in about $30 \%$ of the patients who survive the initial aneurysm rupture and is associated

Departments of Anesthesia and Critical Care, University of Toronto, Toronto Western Hospital, University Health Network, Ontario, Canada

Address for correspondence:

Dr. Lakshmikumar Venkatraghavan, Department of Anesthesia, Toronto Western Hospital, 399, Bathurst Street, Toronto, Ontario, M5T 2S8 Canada. E-mail: Lashmi.Venkatraghavan@uhn.ca 
with poor outcome, accounting for about one-quarter of attributable disability and mortality from ruptured aneurysms ${ }^{[3]}$ The association between anaemia and poor clinical outcomes is consistent across all patients with $\mathrm{SAH}$, although is more pronounced in those with more severe disease. ${ }^{[2,4]}$

As haemoglobin $(\mathrm{Hb})$ level is a major determinant of blood arterial oxygen content, it is hypothesised that treating anaemia with packed red blood cell (PRBC) transfusions may decrease the degree of cerebral ischemia by increasing the blood oxygen carrying capacity. The benefit of PRBC transfusion in these patients remains uncertain, and studies addressing the role of PRBC transfusion in patients with SAH have produced conflicting results. ${ }^{[5,6]}$ Physiologic studies have shown an increase in cerebral oxygen delivery and brain tissue oxygen tension but the effect of this on brain metabolism is not clear. ${ }^{[7,8]}$ Physiologically the resulting rise in cerebral oxygen delivery attained by raising $\mathrm{Hb}$ levels may be offset by the associated increase in blood viscosity with resultant decrease in CBF. ${ }^{[9,10]}$ However, increased oxygen carrying capacity does not imply oxygen unloading and correction of tissue hypoxia as transfused blood often has very low 2,3 DPG, which make the unloading of oxygen difficult. ${ }^{[11]}$ In addition, transfusion may reduce levels of endogenous vasodilators such as nitric oxide ${ }^{[12]}$ and have pro-inflammatory effects, which could worsen the degree of arterial vasospasm. ${ }^{[13]}$

Currently there is little information in the literature regarding the optimal $\mathrm{Hb}$ level to guide transfusion of PRBC. In the normal brain cerebral vasodilatation occurs with $\mathrm{Hb}<10 \mathrm{~g} / \mathrm{dl}^{[14]}$ and cerebral hypoxia does not become evident until $\mathrm{Hb}$ is $<6 \mathrm{~g} / \mathrm{dl} .{ }^{[15]}$ However animal models of brain ischaemia suggest that cerebral hypoxia occurs with an $\mathrm{Hb}<10 \mathrm{~g} / \mathrm{dl}$ suggesting that the injured brain has a markedly reduced tolerance for impaired oxygen delivery. ${ }^{[16]}$ This is supported by clinical data showing that $\mathrm{Hb}>11 \mathrm{~g} / \mathrm{dl}$ is associated with improved outcome after $\mathrm{SAH},{ }^{[17,18]}$ although as stated above it is not clear that increases in $\mathrm{Hb}$ by PRBC transfusion portend the same improved outcome as in patients with native $\mathrm{Hb}$ above $11 \mathrm{~g} / \mathrm{dL}$. A large survey of North American intensivists and neurosurgeons found considerable variability in the $\mathrm{Hb}$ level that they considered acceptable for SAH patients although most said that they would lower their threshold for transfusion in the presence of VS. ${ }^{[19]}$

\section{Objectives}

The aim of our study was to identify the clinical factors associated with red blood cell transfusion after SAH and to determine if transfusion practices are affected by the diagnosis of VS in patients needing mechanical ventilation following aneurysmal SAH.

\section{METHODS}

\section{Study design}

We conducted a retrospective cohort study of consecutive adult patients with aneurysmal SAH admitted to intensive care unit and who received mechanical ventilation in our institution between April 2006 and March 2009.

\section{Subjects and settings}

We included all patients (pre and post intervention) who were 18 years of age or older with admitting diagnosis of $\mathrm{SAH}$, who received mechanical ventilation and who had documented intracranial aneurysm on computerised tomographic angiography or digital subtraction angiography. We excluded patients with non-aneurysmal SAH and those who died within first 72 hours after the diagnosis of SAH.

\section{Data source collection}

The electronic patient record was reviewed for all the identified patients. The data extracted include patient demographics, grade of SAH (World Federation of Neurological Surgeons (WFNS) grade and Fisher grade), treatment of aneurysm, starting and lowest $\mathrm{Hb}$ levels, transfusion data, and the presence or absence of vasospasm.

\section{Institutional management of SAH}

All patients were treated according to a standard policy that included preoperative resuscitation, early aneurysm occlusion and aggressive prevention and treatment of intracranial hypertension and vasospasm. Management of SAH was consistent with published guidelines ${ }^{[20,21]}$ and details have been described elsewhere. Because $\mathrm{Hb}$ concentration of $10 \mathrm{~g} / \mathrm{l}$ is thought to represent an optimal balance between the flow enhancing effects of a lower viscosity and sufficient oxygen carrying capacity, and because this remain common transfusion threshold, we used this level to define anaemia. ${ }^{[5,22]}$ The decision to transfuse was not made into a protocol and was made on an individual basis by the treating physician.

We defined VS as the presence of all three of the following: (1) There was a change in neurologic status not attributable to another aetiology (seizure, sedation, hydrocephalus); (2) Radiological evidence of moderate to severe vasospasm (vessel diameter narrowed more than one-third) (3) Symptoms were sufficiently severe needing treatment with intravenous fluid boluses, hemodynamic augmentation with vasopressors or inotropes or underwent cerebral angioplasty or local vasodilator infusion. ${ }^{[23]}$

\section{Outcome}

Outcome was the presence of any PRBC transfusion during ICU stay. We also collected data on the number of units 
transfused and the timing of transfusion, and whether PRBC transfusion occurred after the diagnosis of VS.

\section{Statistical analysis}

Descriptive statistics were used to characterise baseline clinical characteristics and SAH data. Student $t$-test, Chi-square, Fisher Exact, and Kolmogorov-Smirnov tests were used to compare continuous and categorical parametric and non-parametric data as appropriate. The candidate predictors for multivariate model were selected by screening with univariate analysis with a threshold for inclusion of $P<0.25$. Multiple logistic regression was used to determine independent risk factors for transfusion. Data are reported as mean $+\mathrm{SD}$, median (range), n (\%) for categorical variables and adjusted odds ratio [AOR; $95 \%$ confidence intervals (CI)]. Statistical significance was defined as a $P \leq 0.05$.

The study protocol was approved by the research Ethics board of the institution.

\section{RESULTS}

During the 3-year study period, 298 patients were admitted to the Intensive care unit with a diagnosis of SAH of whom 100 patients met the inclusion criteria. Four additional patients were excluded due to incomplete data, resulting in a final study cohort of 96 patients. Baseline characteristics of the study cohort are shown in Table 1.

\section{Anaemia and transfusion}

$\mathrm{Hb}$ concentration $<100 \mathrm{~g} / 1$ were observed in $64(67 \%)$ patients of whom 27 (28\%) were transfused a total of 48 units of packed RBC (average 1.8 units/patient) with a mean pre transfusion $\mathrm{Hb}$ concentration of $69.8 \mathrm{~g} / \mathrm{l}$. Baseline characteristics of patients who received transfusion are shown in Table 2 . The median $\mathrm{Hb}$ values of patients who had transfusion and who didn't had transfusion were 75 and $82 \mathrm{~g} / 1$. Transfused patients were more likely to be female, have severe baseline neurological dysfunction (WFNS 4 or 5) or large amount of blood on their CT scans (Fisher grade 3 or 4 ) or have developed VS.

\section{Vasospasm, anaemia and transfusion}

Incidence of VS was 39\% (38/96). Anaemia was more prevalent in the patients who developed VS than those without VS ( $84 \%$ compared to $53 \%$, respectively). Transfusion rates were higher among the patients with anaemia who developed VS $(36 \%)$ than those who did not develop VS (22\%). There were no differences in the $\mathrm{Hb}$ values before PRBC transfusion between groups $(68.5 \mathrm{~g} / \mathrm{L}$ in patients with VS vs. 70.3 in patients without VS; g/L; $P=0.57$ ). Out of 14 vasospasm patients who received a transfusion, 11 had transfusion after the onset of vasospasm [Table 3]. Following univariate screening, gender, WFNS grade, Fisher grade and the development of VS met criteria for inclusion in the final multivariate model. None of the covariates was independently associated with transfusion. Presence or absence of VS was not found to be independently associated with transfusion [Table 4].

\section{DISCUSSION}

We report a retrospective cohort study evaluating transfusion practices in a sample of critically ill patients with SAH. We observed that anaemia is common patients with SAH who were admitted to ICU, needing mechanical ventilation. Presence or absence of vasospasm did not increase the transfusion threshold as measured by pre-transfusion $\mathrm{Hb}$. However, $78 \%$ of transfusions in patients who developed vasospasm happened after the diagnosis of vasospasm.

\section{Anaemia in SAH}

Anaemia is common in patients with SAH and the aetiology is likely multifactorial. ${ }^{[1,24]}$ The development of anaemia has been independently associated with morbidity and mortality even after controlling other confounding factors such as age, grade, vasospasm etc. ${ }^{[25]}$ It is not clear whether anaemia is a marker of disease severity or the low $\mathrm{Hb}$ concentration itself contributes to worse outcomes. ${ }^{[26]}$ Poor clinical grades at presentation is one of the risks for the development

\section{Table 1: Demographics}

\begin{tabular}{lc}
\hline Age (years. mean \pm SD) & $54 \pm 14$ \\
Length of stay in ICU (days. mean \pm SD) & $11 \pm 12$ \\
Gender, male N $(\%)$ & $33(34 \%)$ \\
WFNS grade N (\%) & \\
1 & $4(4 \%)$ \\
2 & $19(20 \%)$ \\
3 & $29(30 \%)$ \\
4 & $30(31 \%)$ \\
5 & $14(15 \%)$ \\
FISHER grade N (\%) & \\
1 & $3(3 \%)$ \\
2 & $17(18 \%)$ \\
3 & $40(42 \%)$ \\
4 & $36(38 \%)$ \\
Aneurysm Treatment $(\mathrm{N})$ & $36: 34$ \\
Coiling: Clipping & \\
Clinical Vasospasm N $(\%)$ & $38(39.5 \%)$ \\
Received any Transfusion N (\%) & $27(28 \%)$ \\
Starting Hb, (g/L) mean $\pm S D$ & $135 \pm 18$ \\
Nadir Hb, $(\mathrm{g} / \mathrm{L})$ mean $\pm S D$ & $91 \pm 20$ \\
\hline Hb= Haemoglobin, WFNS= World Federation of Neurological Surgeons
\end{tabular}


Table 2: Baseline characteristics and crude associations with transfusion

\begin{tabular}{|c|c|c|c|}
\hline $\begin{array}{l}\text { Patients with } \\
\text { Anaemia }(n) \\
64 / 96\end{array}$ & $\begin{array}{c}\text { Transfusion } \\
27\end{array}$ & $\begin{array}{c}\text { No } \\
\text { transfusion } \\
37\end{array}$ & $P$ value \\
\hline Age (mean $\pm S D)$ & $54.5 \pm 11.8$ & $56.0 \pm 16.8$ & 0.379 \\
\hline Sex (Male:Female) & $5: 22$ & 10:27 & 0.041 \\
\hline WFNS grade $\mathrm{N}(\%)$ & & & 0.233 \\
\hline 1 & $0(0 \%)$ & $4(6 \%)$ & \\
\hline 2 & $8(30 \%)$ & $11(16 \%)$ & \\
\hline 3 & $10(37 \%)$ & $19(28 \%)$ & \\
\hline 4 & $7(26 \%)$ & $23(33 \%)$ & \\
\hline 5 & $2(7 \%)$ & $12(17 \%)$ & \\
\hline FISHER grade (\%) & & & 0.222 \\
\hline 1 & $2(7 \%)$ & $2(5 \%)$ & \\
\hline 2 & $7(26 \%)$ & $8(21 \%)$ & \\
\hline 3 & $10(37 \%)$ & $15(40 \%)$ & \\
\hline 4 & $8(30 \%)$ & $12(32 \%)$ & \\
\hline $\begin{array}{l}\text { Starting Hb } \\
(\text { mean } \pm S D)\end{array}$ & $124.2 \pm 15.6$ & $133.5 \pm 14.3$ & 0.15 \\
\hline $\begin{array}{l}\text { Lowest Hb } \\
(\text { mean } \pm S D)\end{array}$ & $69.4 \pm 9.5$ & $87.2 \pm 8.8$ & 0.001 \\
\hline $\begin{array}{l}\text { Vasospasm- } \\
\text { present }(n=32)\end{array}$ & 14 & 18 & 0.127 \\
\hline $\begin{array}{l}\text { Vasospasm- } \\
\text { absent }(n=32)\end{array}$ & 13 & 19 & \\
\hline
\end{tabular}

Table 3: Baseline characteristics based on vasospasm

\begin{tabular}{lcc}
\hline $\begin{array}{l}\text { Total number } \\
(\boldsymbol{n}=\mathbf{9 6})\end{array}$ & $\begin{array}{c}\text { Vasospasm } \\
\mathbf{( 3 8 )}\end{array}$ & $\begin{array}{c}\text { No vasospasm } \\
\mathbf{( 5 6 )}\end{array}$ \\
\hline Age (mean \pm SD) & $52.3 \pm 13.9$ & $55.1 \pm 14.4$ \\
Gender (female) $(\%)$ & 27 & 36 \\
Coiling & 13 & 23 \\
Clipping & 18 & 16 \\
Starting Hb (mean: & $134.5 \pm 20.8$ & $135.3 \pm 16.7$ \\
SD) (g/L) & & $96.3 \pm 21.5$ \\
Lowest Hb (mean: & $82.9 \pm 15.1$ & \\
SD) (g/L) & & $13(22)$ \\
Transfusion $\mathrm{n}(\%)$ & $14(36)$ & 70.3 \\
Hb before & 68.5 & \\
transfusion. $(\mathrm{g} / \mathrm{L})$ & & \\
\hline Hb= Haemoglobin & &
\end{tabular}

of anaemia. ${ }^{[4]}$ However, the degree of anaemia and severity of haemorrhage does not have direct relationship. ${ }^{[17]}$ High grade SAH is often accompanied by more systemic inflammation contributing to the anaemia of inflammation. ${ }^{[24]}$ In addition, intravascular
Table 4: Multivariate logistic regression analysis for transfusion

\begin{tabular}{lcc}
\hline Source & $\begin{array}{c}\text { Odds } \\
\text { ratio }\end{array}$ & $\begin{array}{c}\text { Confidence } \\
\text { interval }\end{array}$ \\
\hline Gender (female vs. male) & 2.8 & $0.93-8.6$ \\
WFNS grade & 1.0 & $0.59-1.8$ \\
Fisher grade & 0.6 & $0.23-1.2$ \\
Development of clinical VS & 2.2 & $0.85-5.6$
\end{tabular}

WFNS $=$ World Federation of Neurological Surgeons, VS= Vasospasm

expansion with colloid and crystalloid might lead to dilutional anaemia. ${ }^{[26]}$ Studies have shown that anaemia or large reduction in $\mathrm{Hb}$ are associated with infarction, dependency and death and this may be due to delayed ischaemia, multi-organ failure and other complication. ${ }^{[4,25,27]}$

Transfusion trigger in patients with SAH varies. First there is variability in the provider's beliefs. A large survey of North American Intensivists and Neurosurgeons found considerable variability in the $\mathrm{Hb}$ level that they considered acceptable for SAH patients although most said that they would maintain a higher $\mathrm{Hb}$ concentration in the presence of DCI. ${ }^{[19]}$ Interestingly, neurosurgeons were more willing to transfuse than intensivists. While this information gives us some valuable insights into how these patients might be managed, it does not necessary tell us what happens in practice. It is likely that practical decision-making relating to transfusion may be different in real situations, may be influenced by the rest of the health care team and may not always be made by specialist physicians. The Transfusion Requirement in Critical Care (TRICC) trial supports the use of a restrictive transfusion approach in critically ill patients in general but concern remains that such a conservative strategy may not be appropriate for patients at particular risk of end organ ischaemia, including those with impaired cardiac and cerebral oxygen delivery. ${ }^{[28,29]}$

Our cohort group consisted of patients with aneurysmal SAH who were admitted to ICU. Patients who are of higher grade of SAH are usually admitted to ICU, needing mechanical ventilation. These patients are at higher risk for vasospasm and also have high incidence of anaemia. ${ }^{[3]}$ This might limit generalisability of our observations to other population and in comparison to the published literature, where many prior studies evaluating anaemia and transfusion practices in SAH have included both critically ill and less sick patients. ${ }^{[4,5,18,30,31]}$ Our study cohort consisted of a high proportion (more than $75 \%$ ) of patients with WFNS Grade 3 and 4 . This group is unique in that they have high incidence of vasospasm. Incidence of VS after SAH is reported to be around $20-30 \%$ and in our cohort it was around $38 \% .{ }^{[3]}$ 
In spite of variability in transfusion triggers, the percentage of patients transfused and amount of blood transfused is more concerned. Across the various studies, transfusion rates were around $27-61 \%$ and average transfusion around 2-4 units per patient. ${ }^{[5,18,30,31]}$ Our present study also had similar rates. One previous study has shown higher transfusion in patients with VS $(72 \%$ when compared to without VS vs. $22 \%){ }^{[2]}$ however in our study, the transfusion rates were similar in patients with or without VS. The differences might be due to the fact that Kramer et al., study population was quite heterogeneous with majority of patients in their study cohort consisted or good grades of SAH (grade 1or 2)..$^{[2]}$

\section{Vasospasm and anaemia}

There is a complex relationship between anaemia and vasospasm in patients with aneurysmal SAH. Studies have shown that both lower mean and nadir $\mathrm{Hb}$ have been associated with development of radiographic infarctions and VS. ${ }^{[17]}$ However other studies have failed to support this finding. ${ }^{[4,5]}$ In addition, the management of vasospasm typically involves intravascular volume expansion with crystalloid and colloid, which can lead to the development of anaemia. ${ }^{[26]}$ In our study the incidence of anaemia was $84 \%$ in patients who developed vasospasm.

At the same time, correction of anaemia with transfusion of packed cells has failed to show improved outcomes, and packed cell transfusion has not consistently been shown to improve brain oxygen tension. ${ }^{[11]}$ There are good theoretical reasons to maintain a higher $\mathrm{Hb}$ after brain injury; there is variability in the response of brain tissue oxygen (PbtO2) to PRBC transfusion. ${ }^{[7]}$ Even when PRBC transfusion improves $\mathrm{PbtO} 2$, it is not clear whether this improves brain metabolism. ${ }^{[32]}$ Transfused blood may be deficient in or may scavenge endogenous vasodilators such as nitric oxide, contributing to a failure of the normal mechanism that match microcirculatory oxygen supply and demand. ${ }^{[33,34]}$ This is important in SAH because reduced nitric oxide availability has been thought to play a role in the pathogenesis of vasospasm. ${ }^{[34]}$ Further, transfusion has been associated with other short term and long-term complications. ${ }^{[4]}$ Studies have suggested an association between transfusion and the development of vasospasm, but there is a little evidence for the causal relationship..$^{[5]}$ Most of the studies looking into outcomes after transfusion suffer from major methodological limitations. ${ }^{[35]}$ Studies have shown that both anaemia and blood transfusion influenced outcome independently of each other. ${ }^{[4,18,30]}$

\section{Study limitations}

The most important limitation in this study is in the retrospective study design. We were limited to the data recorded in the patient chart. This is also a single centre study and care was not protocolised. Even though we did not include every single clinical variable potentially representing an indication for PRBC transfusion, we did include those most commonly encountered in our clinical practice. Furthermore, relatively small sample size limits the power of the study practice. Transfusions were ordered at the discretion of the clinical teams, and we couldn't exclude the role of individual variability and/or inter-physician heterogeneity.

\section{CONCLUSION}

From our retrospective review, we conclude that the incidence of anaemia is higher in patients with vasospasm. Sex and starting and lowest $\mathrm{Hb}$ levels were the only predictors of transfusion likelihood in aneurysmal SAH while presence of vasospasm was not.

\section{REFERENCES}

1. Le Roux PD. Participants in the International Multi-disciplinary Consensus Conference on the Critical Care Management of Subarachnoid Hemorrhage. Anaemia and transfusion after subarachnoid hemorrhage. Neurocrit Care 2011;15:342-53.

2. Kramer AH, Zygun DA, Bleck TP, Dumont AS, Kassell NF, Nathan B. Relationship between hemoglobin concentrations and outcomes across subgroups of patients with aneurysmal subarachnoid hemorrhage. Neurocrit Care 2009;10:157-65.

3. Longstreth WT Jr, Nelson LM, Koepsell TD, van Belle G. Clinical course of spontaneous subarachnoid hemorrhage: A population-based study in King County, Washington. Neurology 1993;43:712-8.

4. Kramer AH, Gurka MJ, Nathan B, Dumont AS, Kassell NF, Bleck TP. Complications associated with anemia and blood transfusion in patients with aneurysmal subarachnoid hemorrhage. Crit Care Med 2008;36:2070-5.

5. Smith MJ, Le Roux PD, Elliott JP, Winn HR. Blood transfusion and increased risk for vasospasm and poor outcome after subarachnoid hemorrhage. J Neurosurg 2004;101:1-7.

6. Dhar R, Zazulia AR, Videen TO, Zipfel GJ, Derdeyn CP, Diringer MN. Red blood cell transfusion increases cerebral oxygen delivery in anemic patients with subarachnoid hemorrhage. Stroke 2009;40:3039-44.

7. Smith MJ, Stiefel MF, Magge S, Frangos S, Bloom S, Gracias V, et al. Packed red blood cell transfusion increases local cerebral oxygenation. Crit Care Med 2005;33:1104-8.

8. Kurtz P, Helbok R, Claassen J, Schmidt J, Fernadez L, Stuart R, et al. Effect of packed red blood cell transfusion on cerebral oxygenation and metabolism after subarachnoid hemorrhage. Crit Care 2010;14:P341.

9. Gaehtgens P, Marx P. Hemorheological aspects of the pathophysiology of cerebral ischemia. J Cereb Blood Flow Metab 1987;7:259-65.

10. Wood JH, Kee DB Jr. Hemorheology of the cerebral circulation in stroke. Stroke 1985;16:765-72.

11. Walsh TS, McArdle F, McLellan SA, Maciver C, Maginnis M, Prescott RJ, et al. Does the storage time of transfused red blood cells influence regional or global indexes of tissue oxygenation in anemic critically ill patients? Crit Care Med 2004;32:364-71.

12. Doctor A, Platt R, Sheram ML, Eischeid A, McMohan T, Maxey T, et al. Hemoglobin conformation couples erythrocyte S-nitrosothiol content to $\mathrm{O} 2$ gradients. Proc Natl Acad Sci U S A 2005;102:5709-14. 
13. Moore EE. Blood substitutes: The future is now. J Am Coll Surg 2003;196:1-17.

14. Borgstrom L, Johannsson $\mathrm{H}$, Siesjo BK. The influence of acute hormovolemic anemia on cerebral blood flow and oxygen consumption of anesthetized rats. Acta Physiol Scand 1975;93:505-14.

15. McLaren AT, Marsden PA, Mazer CD, Baker AJ, Stewart DJ, Tsui AK, et al. Increased expression of HIF-1alpha, nNOS, and VEGF in the cerebral cortex of anemic rats. Am J Physiol Regul Integr Comp Physiol 2007;292:R403-14.

16. Dexter F, Hindman BJ. Effect of haemoglobin concentration on brain oxygenation in focal stroke: A mathematical modeling study. Br J Anaesth 1997;79:346-51.

17. Naidech AM, Jovanovic B, Wartenberg KE, Parra A, Ostapkovich N, Connolly ES, et al. Higher hemoglobin is associated with improved outcome after subarachnoid hemorrhage. Crit Care Med 2007;35:2383-9.

18. Naidech AM, Drescher J, Ault ML, Shaibani A, Batjer HH, Alberts MJ. Higher hemoglobin is associated with less cerebral infarction, poor outcome, and death after subarachnoid hemorrhage. Neurosurgery 2006;59:775-9.

19. Kramer AH, Diringer MN, Suarez JI, Naidech AM, Macdonald LR, Le Roux PD. Red blood cell transfusion in patients with subarachnoid hemorrhage: A multidisciplinary North American survey. Crit Care 2011;15:R30.

20. Bederson JB, Connolly ES Jr, Batjer HH, Dacey RG, Dion JE, Diringer $\mathrm{MN}$, et al. American Heart Association. Guidelines for the management of aneurysmal subarachnoid hemorrhage: A statement for healthcare professionals from a special writing group of the Stroke Council. American Heart Association. Stroke 2009;40:994-1025.

21. Diringer MN, Bleck TP, Claude Hemphill J $3^{\text {rd }}$, Menon D, Shutter L,Vespa P, et al.NeurocriticalCareSociety.Critical care management of patients following aneurysmal subarachnoid hemorrhage: Recommendations from the Neurocritical Care Society's Multidisciplinary Consensus Conference. Neurocrit Care 2011;15:211-40.

22. Pendem S, Rana S, Manno EM, Gajic O. A review of red cell transfusion in the neurological intensive care unit. Neurocrit Care 2006;4:63-7.

23. Haley EC Jr, Kassell NF, Torner JC. A randomized trial of nicardipine in subarachnoid hemorrhage: Angiographic and transcranial Doppler ultrasound results. A report of the Cooperative Aneurysm Study. J Neurosurg 1993;78:548-53.

24. Sampson TR, Dhar R, Diringer MN. Factors associated with the development of anemia after subarachnoid hemorrhage. Neurocrit Care 2009;12:4-9.

25. Wartenberg KE,Schmidt JM,Claassen J,Temes RE,Frontera JA, Ostapkovich $\mathrm{N}$, et al. Impact of medical complications on outcome after subarachnoid hemorrhage. Crit Care Med 2006;34:617-23.

26. Awad IA, Carter LP, Spetzler RF, Medina M, Williams FC Jr. Clinical vasospasm after subarachnoid hemorrhage: Response to hypervolemic hemodilution and arterial hypertension. Stroke 1987;18:365-72.

27. Kurtz P, Schmidt JM, Claassen J, Carrera E, Fernandez L, Helbok R, et al. Anemia is associated with metabolic distress and brain tissue hypoxia after subarachnoid hemorrhage. Neurocrit Care 2010;13:10-6.

28. Hebert PC, Wells G, Blajchman MA, Marshall J, Martin C, Pagliarello G, et al. A multicenter, randomized, controlled clinical trial of transfusion requirements in critical care. Transfusion Requirements in Critical Care Investigators, Canadian Critical Care Trials Group. N Engl J Med 1999;340:409-17.

29. Hebert PC, Yetisir E, Martin C, Blajchman MA, Wells G, Marshall J, et al. Is a low transfusion threshold safe in critically ill patients with cardiovascular diseases? Crit Care Med 2001;29:227-34.

30. Levine J, Kofke A, Cen L, Chen Z, Faerber J, Elliott JP, et al. Red blood cell transfusion is associated with infection and extracerebral complications after subarachnoid hemorrhage. Neurosurgery 2010;66:312-8.

31. Broessner G, Lackner P, Hoefer C, Beer R, Helbok R, Grabmer $\mathrm{C}$, et al. Influence of red blood cell transfusion on mortality and long-term functional outcome in 292 patients with spontaneous subarachnoid hemorrhage. Crit Care Med 2009;37:1886-92.

32. Zygun DA, Nortje J, Hutchinson PJ, Timofeev I, Menon DK, Gupta AK. The effect of red blood cell transfusion on cerebral oxygenation and metabolism after severe traumatic brain injury. Crit Care Med 2009;37:1074-8.

33. Roback JD, Neuman RB, Quyyumi A,Sutliff R. Insufficientnitric oxide bioavailability: A hypothesis to explain adverse effects of red blood cell transfusion. Transfusion 2011;51:859-66.

34. Pluta RM. Dysfunction of nitric oxide synthases as a cause and therapeutic target in delayed cerebral vasospasm after SAH. Neurol Res 2006;28:730-7.

35. Rosenberg NF, Koht A, Naidech A. Anemia and transfusion after aneurysmal subarachnoid hemorrhage. J Neurosurg Anesthesiol 2013;25:66-74.

How to cite this article: Venkatraghavan L, Tymianski S, Singh J. Do transfusion requirements increase after the diagnosis of vasospasm in patients with aneurysmal subarachnoid haemorrhage?. J Neuroanaesthesiol Crit Care 2015;2:38-43.

Source of Support: Nil, Conflict of Interest: None declared. 